\title{
América Latina em perigo: imperialismo e pan-americanismo nos escritos de César Zumeta
}

\section{Latin America in danger: imperialism and Pan-Americanism in the writings of Cesar Zumeta}

\author{
Regiane Cristina Gouveia ${ }^{1}$
}

\begin{abstract}
Resumo
Este artigo analisa, a partir da obra El continente enfermo (1899), do venezuelano César Zumeta (1860-1955), como o debate acerca do pan-americanismo e dos imperialismos na América Latina, em fins do século XIX e início do XX, aparece nos escritos desse autor. Examina também as soluções que o escritor propôs para os problemas do continente, que caracterizou como enfermo devido à desorganização política e às disputas e hostilidades entre as repúblicas latino-americanas. Em um contexto de modernização da América Latina, imperialismos, europeu e norte-americano, e pan-americanismo, Zumeta preocupou-se em denunciar os perigos que cercavam o continente e que poderiam levar a perdas territoriais, de independência e soberania, além da perda da tradição cultural latina. Ao fazer isso, o autor contribuiu para o fortalecimento de correntes de pensamento latino-americano que buscavam resistir à influência política, econômica e moral, norte-americana e europeia.
\end{abstract}

Palavras-chave: Intelectuais; América Latina; relações interamericanas.

\begin{abstract}
This article examines the work from El Sick Continent (1899), the Venezuelan César Zumeta (1860-1955) as the debate about Americanism and imperialism in Latin America in the late nineteenth and early twentieth centuries, appears in written by this author. Also examines the solutions that the writer proposed to the continent's problems, which characterized as ill due to the political disorganization and disputes and hostilities between the Latin American republics. In a context of modernization in Latin America, imperialism, European and North American, and Pan Americanism, Zumeta concerned to denounce the dangers surrounding the continent and that could lead to territorial losses, independence and sovereignty, and the loss Latin cultural tradition. By doing this, the author has contributed to the strengthening of current Latin American thought that sought to resist the political, economic and moral, North American and European influence.
\end{abstract}

Keywords: Intellectuals; Latin America, Inter-American relations.

Artigo recebido em: 27/07/2014

Artigo aprovado para publicação em: 19/11/2014

\footnotetext{
${ }^{1}$ Doutoranda no Programa de Pós-Graduação em História das Ciências e da Saúde da Fundação Oswaldo Cruz (FIOCRUZ). Título da pesquisa: América Latina enferma: racismo, positivismo e hispanidad no pensamento político latino-americano em fins do século XIX e inicio do XX. Bolsista do PDSE/CAPES. E-mail: regiane_gouveia@yahoo.com.br.
}

\section{GANPHLAC}

Revista Eletrônica da ANPHLAC, ISSN 1679-1061, N. 17, p. 254-281, jul./dez. 2014. http://revista.anphlac.org.br/ 
Em meados do século XIX o desenvolvimento científico ${ }^{2}$ e tecnológico proporcionou grande entusiasmo entre a intelectualidade europeia e americana. As descobertas que surgiram, sobretudo nos campos da biologia, da química e da medicina, não apenas propiciaram significativo êxito nessas áreas, como também passaram a ser aplicadas para explicar o homem e a sociedade. A literatura médica ganhou espaço entre a intelectualidade da América Latina ${ }^{3}$, e sua linguagem foi amplamente empregada por intelectuais preocupados com o futuro do continente.

Nesse contexto, surgiu uma ensaística que procurou analisar a realidade latinoamericana por meio do paradigma das ciências naturais. Surgiram proposições utilizando o vocabulário médico que comparavam a América a um corpo enfermo e proliferaram conjeturas acerca da incapacidade do continente de incorporar a modernização e alcançar o "progresso", ideais muito cobiçados no período. Tal modo de interpretar a realidade latino-americana estava relacionado à autoridade que a ciência adquirira na época, uma vez que passou a ser percebida como uma forma de conhecimento neutro, empírico e confiável (STEPAN, 2005, p. 75).

Este trabalho procura analisar, a partir da obra El continente enfermo (1899), do escritor venezuelano César Zumeta, como o debate, na virada do século XIX para o XX, sobre o pan-americanismo e os imperialismos (europeu e norte-americano), na América Latina, aparece nos seus escritos. Também examina as soluções que o autor propôs para

\footnotetext{
${ }^{2}$ No século XIX houve uma proliferação de inventos com os desenvolvimentos na química, física e biologia. Nesse momento, surgiu o motor de explosão, o telefone, o microfone, a radiotelegrafia, a lâmpada elétrica, o transporte público mecanizado, a máquina de escrever, uma intensa circulação de notícias impressas a baixo custo, as primeiras fibras sintéticas, a seda artificial, o plástico sintético. E muitas dessas novidades surgiram em um transcurso de quinze anos, entre 1867 e 1881. (BARRACLOUGH, 1964, p. 45)

${ }^{3}$ Não obstante estejamos conscientes da complexidade que envolve o termo "América Latina", bem como as ambiguidades e as contradições inerentes a ele, neste trabalho utiliza-se esse nome para fazer referência à antiga região de colonização espanhola e portuguesa. Para os propósitos deste trabalho, optou-se por não discutir essa questão. Uma ampla bibliografia tem discutido a origem e difusão do nome "América Latina". A esse respeito, ver os trabalhos de: ARDAO, Arturo. Genesis de la idea y el nombre de América Latina. Caracas: Centro de Estudios Latinoamericanos "Rómulo Gallegos", 1980; QUIJADA, Mónica. Sobre el origen y difusión del nombre 'América Latina' (o una variación heterodoxa en torno al tema de la construcción social de la verdad). Revista de Indias, v. LVIII, n. 214, 1998; GRANADOS, Aimer; MARICHAL, Carlos. Construcción de las identidades latinoamericanas: ensayos de historia intelectual siglos XIX y XX. México D.F.: El Colegio de México, 2009.
}

\section{GANPHLAC}

Revista Eletrônica da ANPHLAC, ISSN 1679-1061, No. 17, p. 254-281, jul./dez. 2014. http://revista.anphlac.org.br/ 
os problemas que identificava no continente, caracterizado como enfermo em decorrência da desorganização política e das disputas e hostilidades entre as repúblicas latino-americanas.

O escritor César Zumeta foi um intelectual de prestígio em sua época, ${ }^{4}$ ocupou importantes cargos políticos e de representação diplomática. Teve ampla e profícua vida intelectual, escrevendo, ininterruptamente, por mais de vinte anos, para variados jornais na América e na Europa, tratando de temas políticos, sociais, econômicos e culturais latino-americanos. ${ }^{5}$ Fundou muitos jornais, como El Anunciador (1883) e El Pueblo (1890), em Caracas; América (1900), em Paris, e La Semana (1906-1908), em Nova York. Trabalhou ainda na redação de conhecidos jornais da época, colaborando com o Unión Ibero-americana (1900), de Madri; El Americano (1904) e La Prensa (1916), de Nova York; El Mundo (1908), de La Habana; e El Litoral Atlantico (1908), de São Salvador (ZUMETA, 1961, p. 9-10). Esse autor também contribuiu na divulgação de trabalhos de escritores venezuelanos nos Estados Unidos e na Europa, bem como traduziu e divulgou escritores europeus e americanos na Venezuela.

Zumeta foi reconhecido por importantes intelectuais seus coetâneos, como José Martí, José Enrique Rodó, Rufino Blanco Fombona, Francisco García Calderón, entre outros, que comentaram a sua produção e escreveram notas elogiosas a seu respeito. No periódico Patria, publicado em setembro de 1894, Martí dedicou uma longa nota ao autor venezuelano. $\mathrm{O}$ escritor cubano, fazendo referência à iniciativa de Zumeta de criar a Casa Editorial em Nova York, afirmou que esse autor vinha contribuindo para valorizar o que era característico de nuestra América e arrancar o que lhe era daninho. Segundo Martí (apud INSAUSTI, 1963, p. 12), Zumeta, “crítico sagaz, y estilista de mérito y color, amigo de lo grande y de lo joven, es el alma de la empresa que hace llamamiento a todas las fuerzas vivas de la América pensadora y literaria", de modo que

\footnotetext{
${ }^{4}$ Sua produção foi publicada sob muitos pseudônimos: Ignotus, Blumentha, Luis Avila e Junius.

${ }^{5}$ Zumeta não publicou nenhuma obra em vida. Segundo Luis Beltrán Guerrero, o escritor venezuelano sempre manteve uma "certa superior indiferença por sua própria obra", embora tenha guardado recortes do material publicado e alguns inéditos. El continente enfermo foi publicado em 1899 como folheto. Posteriormente, em 1961, foi reeditado com compilações de vários artigos escritos por Zumeta ao longo do século XX, formando uma obra maior sob o mesmo título, publicado pela Colección Rescate. É essa coletânea que utilizaremos neste trabalho. Em 1962 foi publicado Tiempo de América y Europa (18891916), e no ano seguinte, Las potencias y la intervención en Hispanoamérica, essas duas últimas pela Colección Venezuela Peregrina.
}

\section{GANPHLAC}

Revista Eletrônica da ANPHLAC, ISSN 1679-1061, N. 17, p. 254-281, jul./dez. 2014. http://revista.anphlac.org.br/ 
cada povo, do México a Cuba e até Argentina e Chile, começavam a abrir espaço às correntes do pensamento americano.

O venezuelano Rufino Blanco Fombona, em Cuentos de poeta, publicado em $1900,{ }^{6}$ dedicou algumas linhas a descrever Zumeta, caracterizando-o como

alma cambiante y compleja. Es bueno y malo. Su ironía es malvada; y se ríe, cuando habla, de un modo siniestro. Pertenece a los buenos días en que se obsequiaba a un huésped, en una copa labrada, con un tósigo. Sus flores están sutilmente envenenadas. Desvalija falsas reputaciones, en dos minutos, con una habilidad calabresa. Pero hay una cosa indiscutible: que la compañía de Zumeta es siempre interesante. (BLANCO FOMBONA apud ZUMETA, 1963, p. 10-11)

Em 1912, Francisco García Calderón, na obra La creación de un continente, comentou positivamente o trabalho de Zumeta. Em sua concepção, o venezuelano, a partir de El continente enfermo, dava início a uma nova escola que, frente ao perigo comum que cercava a América Latina, se empenhava em estudar os problemas coletivos e em defender a autonomia moral do continente (GARCÍA CALDERÓN, apud INSAUSTI, 1963, p. 22).

César Zumeta ganhou notoriedade em vida. Sua obra, ao longo da primeira metade do século XX, influenciou muitos estudos acerca do continente. Esse autor, embora reconhecesse os problemas da América Latina e, em determinados momentos, apresentasse uma concepção pessimista em relação ao seu porvir, propunha soluções concretas para a situação do continente e, diferentemente de muitos intelectuais do período, conforme veremos mais adiante, valorizava a tradição cultural latina.

\section{Cesar Zumeta e a Venezuela}

Após os processos de independência na América Hispânica, as nascentes repúblicas tinham uma complexa tarefa a realizar: formar Estados Nacionais a partir das ruínas do Império Espanhol. Os longos anos de guerras trouxeram consequências

\footnotetext{
${ }^{6}$ No ano anterior, Blanco Fombona, ao lamentar a forma como a Venezuela tratava seus "homens ilustres", afirmara que esse país vinha sendo cruel com grandes homens: "para Belo, a calumnia, para Bonalde el desdén, para Zumeta la indiferencia". (BLANCO FOMBONA apud ZUMETA, 1963, p. 10)
}

\section{GANPHLAC}

Revista Eletrônica da ANPHLAC, ISSN 1679-1061, Nº. 17, p. 254-281, jul./dez. 2014. http://revista.anphlac.org.br/ 
penosas, como um grande empobrecimento com a destruição das riquezas produzidas em plantações, criação de gado e minas; o esgotamento do tesouro público; além de disputas locais entre os líderes políticos, fazendo com que grande parte dessas repúblicas mergulhasse em um duradouro período de guerras civis, que se estenderam até fins do século XIX e início do XX (PRADO, 2004, p. 69). ${ }^{7}$

Ao longo do Oitocentos, a Venezuela passou por diversos conflitos internos. As lutas caudilhistas levaram a um extenso período de instabilidade política e econômica. Alguns dos caudilhos conseguiram permanecer anos no poder, como António Guzmán Blanco, ${ }^{8}$ que governou a Venezuela por três vezes. Aqueles que governaram nos períodos em que ele não estava no poder assumiram sob a sua égide. Através de fáceis transições e reformulações da Constituição, foi alternadamente presidente e ministro Plenipotenciário na Inglaterra e França, permanecendo no cenário político venezuelano por cerca de dezoito anos. ${ }^{9}$

É importante destacar o segundo governo de Guzmán Blanco (1879-1884), cujas principais medidas versam sobre a modernização do país em distintas esferas e repercutiu nos governos que o precederam. Nesse momento, ele estimulou a criação do sistema de linhas telegráficas e a construção de ferrovias. A solução encontrada para levar a cabo tal empreendimento foi garantir às empresas, inglesas e alemãs, um retorno de $7 \%$ dos seus investimentos. As empresas concessionárias não conseguiram receber esse valor através dos serviços e a República teve que cobrir a porcentagem estabelecida, trazendo endividamentos para o país (LUCCA, 2013, p. 94). Governos posteriores tiveram que contrair grandes empréstimos, como o de 1896, com o Disconto Gesellschaft de Berlim, no governo de Joaquín Crespo ${ }^{10}$, o que levaria a conflitos no início do século XX.

\footnotetext{
${ }^{7}$ Sobre a América Latina ao longo do século XIX e XX, ver: PRADO, Maria Ligia; PELLEGRINO, Gabriela. História da América Latina. São Paulo: Contexto, 2014.

${ }^{8}$ António Guzmán Blanco assumiu o poder na Venezuela em 1870, através da chamada Revolução de Abril, que destituiu do poder o general José Ruperto Monagas (1831-1880), e permaneceu até 1877. Seu segundo governo foi entre 1879 e 1884 e, por fim, entre os anos de 1886 e 1888. Sobre Guzmán Blanco, ver: ALCANTARA, Tomas Polanco. Guzmán Blanco. Caracas: Ediciones GE, 2002.

${ }^{9}$ Somente na década de 1890 ele desapareceu da vida política de seu país, quando, no governo de Raimundo Andueza Palacio (1890-1892), vieram a público os contratos que Guzmán Blanco fazia para fomento próprio e que levou à perda territorial da Guiana Essequiba para a Inglaterra.

${ }^{10}$ Joaquín Crespo governou a Venezuela por duas vezes, entre 1884-1886 e 1892-1898.
}

\section{GANPHLAC}

Revista Eletrônica da ANPHLAC, ISSN 1679-1061, Nº. 17, p. 254-281, jul./dez. 2014. http://revista.anphlac.org.br/ 
Nas últimas décadas do século XIX, a Venezuela também passou por conflitos externos em decorrência de disputas fronteiriças com a Inglaterra. ${ }^{11} \mathrm{Em} 1896$, um episódio inflamou os ânimos nacionais, quando soldados ingleses, que procuravam estender os limites de seu território até o rio Yuruari, foram severamente repelidos pelos soldados venezuelanos, que os aprisionaram e removeram a bandeira inglesa. A Inglaterra considerou tal fato uma grave ofensa e reclamou ante o governo da Venezuela, que se recusou a atendê-la. Na iminência de um conflito, o então presidente dos Estados Unidos, Grover Cleveland (1837-1908), invocou a Doutrina Monroe, não obstante a insatisfação da coroa inglesa. No ano seguinte, a Inglaterra e os Estados Unidos impuseram à Venezuela uma arbitragem internacional, composta por dois árbitros norte-americanos, dois ingleses e um russo, sendo negado ao país reclamante o direito de nomear seus próprios árbitros. Em 1899, a Venezuela foi despojada de 159.500 quilômetros quadrados de seu território, fato que não aceitou e contra o qual recorreu diversas vezes. ${ }^{12}$

Foi em um contexto de instabilidade política e formação do Estado Nacional que nasceu em 1860, em San Felipe, ${ }^{13}$ César Zumeta. Oriundo de família humilde, foi abandonado pelos pais e ficou aos cuidados de uma família com posses. Desde cedo, aprendeu latim e alemão. Frequentou o Colegio Santa María, tendo como professores proeminentes intelectuais venezuelanos como Augustín Aveledo, Luís Sanojo, M. M. Urbanja e Elías Rodríguez. Zumeta cursou a Faculdade de Direito na Universidad Central de Venezuela, mas não concluiu devido ao desterro sofrido, em 1883, quando se iniciou no jornalismo de oposição ao governo de Guzmán Blanco, fundando o $E l$ Anunciador (CAPPELLETTI, 1994, p. 307). ${ }^{14}$

Em 1884, Zumeta regressou à Venezuela, governada por Joaquín Crespo, sucessor de Guzmán Blanco. Novamente foi preso e, em seguida mandado, para os Estados Unidos, onde entrou em contato com muitos intelectuais hispano-americanos

\footnotetext{
${ }^{11}$ Em 1887, a Venezuela e a Inglaterra já haviam rompido relações por causa da Guiana.

${ }^{12}$ Somente em 1966, em Genebra, a Grã-Bretanha e a futura República Cooperativa da Guiana reconheceram o reclamo da Venezuela (LUCCA, 2013, p. 108).

${ }^{13}$ San Felipe é um município do estado de Yaracuy, localizado a 270km de Caracas.

${ }^{14}$ Antes disso, por ocasião das festas centenárias do Libertador Simón Bolívar, Zumeta havia dedicado seu primeiro opúsculo à Guzmán Blanco, denominando-o de "ilustre protector", "regenerador de Venezuela" y "Presidente Constitucional de la República".
}

\section{GANPHLAC}

Revista Eletrônica da ANPHLAC, ISSN 1679-1061, N. 17, p. 254-281, jul./dez. 2014. http://revista.anphlac.org.br/ 
que também tinham sido banidos de seus países, como o cubano José Martí e o venezuelano Pérez Bonalde. Lá, passou a integrar a redação do La América (18841889), permanecendo até 1890, quando foi eleito um novo presidente na Venezuela, Raimundo Andueza Palacio, que não ascendia sob a vontade de Guzmán Blanco, como vinha ocorrendo desde 1870.

Zumeta foi convidado a retornar à Venezuela, onde assumiu a direção do periódico El Pueblo; no ano seguinte, foi designado diretor do jornal El Universal, além de ter sido cofundador e colaborador da Revista Universal Ilustrada. Entretanto, quando, em 1892, o general Joaquín Crespo voltou ao poder através da Revolución Legalista, Zumeta teve novamente que abandonar seu país.

Entre os anos de 1894 e 1895, Zumeta permaneceu na Venezuela participando da fundação da revista Cosmópolis, mas logo voltou para os Estados Unidos. Em 1901, retornou ao seu país e foi nomeado senador no governo do General Cipriano Castro. No ano seguinte, a Venezuela passou por uma difícil situação: a queda no preço do café e outros problemas - provenientes das lutas que os governos que assumiam tinham que empreender para se manterem no poder - impossibilitaram o pagamento de suas dívidas, principalmente com o Disconto Gesellchaft, de Berlim (LUCCA, 2013, p. 94).

Nesse contexto, Inglaterra e Alemanha, alarmadas com a possibilidade de insolvência econômica para qual a Venezuela parecia caminhar, bloquearam, em 9 de dezembro de 1902, o porto de La Guaira; quatro dias depois, bombardearam Puerto Cabello, se instalando em frente à fortaleza de San Carlos; logo, afundaram a embarcação Crête-à-Pierrot, na desembocadura do rio Orinoco. A essas potências se somaram Itália, França, Bélgica, Holanda, Espanha e México, todas preocupadas com o não cumprimento das dívidas da Venezuela (LUCCA, 2013, p. 116).

O governo dos Estados Unidos interveio nesse conflito invocando novamente a Doutrina Monroe. ${ }^{15}$ Em fevereiro de 1903, foi firmado o Protocolo de Washington,

\footnotetext{
${ }^{15}$ A princípio, Theodore Roosevelt permitiu o bloqueio imposto pelas potências europeias, mas, com o acirramento da situação, em 1903 interviu no conflito. De acordo com Robert Smith, após a destruição do Forte de San Carlos, que guardava os estreitos de Maracaibo, e outros incidentes, Roosevelt informou ao embaixador da Alemanha que o Almirante George Dewey tinha ordens secretas de manter-se de prontidão e, se fosse necessário, estar em águas venezuelanas em uma hora. Esse almirante se encontrava na Ilha de Culebra, em Porto Rico, com uma frota de 54 navios. Antes disso, Roosevelt havia declarado
}

\section{GANPHLAC}

Revista Eletrônica da ANPHLAC, ISSN 1679-1061, N. 17, p. 254-281, jul./dez. 2014. http://revista.anphlac.org.br/ 
autorizado pelo governo venezuelano, no qual ficava estabelecido que a Venezuela se comprometia em ceder ao governo britânico, a partir do mês de março daquele ano, $30 \%$ em pagamentos mensais das rendas aduaneiras de La Guaira e Puerto Cabello. Após assinatura desse documento, as armadas europeias abandonaram a costa venezuelana, cessando o bloqueio (LUCCA, 2013, p. 117). Zumeta, nessa ocasião, colaborou com o governo do presidente Cipriano Castro, sendo nomeado cônsul-geral na Inglaterra e encarregado de mudar a imagem da Venezuela na Europa.

Cabe lembrar que o bloqueio e as agressões à Venezuela tiveram repercussão internacional, resultando na criação da chamada Doutrina Drago. Essa doutrina foi elaborada pelo jurista e ministro das Relações Exteriores da Argentina, Luis María Drago (1859-1921), que, em 1903, se opôs ao uso das Forças Armadas de um país contra outro, no intuito de cobrar o pagamento de dívidas. Somente seria aprovada na Segunda Conferencia de Haia, em 1907 (OLIVEIRA LIMA, 1953, p. 132-133). A Doutrina Drago se baseava no argumento de que os credores, independentemente do país de que procedessem, não poderiam reclamar através da luta armada dos seus governos contra os devedores por motivo da cessação do pagamento dos juros, pois, na taxa de juros estabelecida e nas negociações realizadas já se presumiam e estavam subentendidos os riscos da transação (BAGGIO, 1999, p. 76).

O escritor do El continente enfermo regressou à Venezuela em 1908, quando Juan Vicente Gómez, presidente vitalício, assumiu o poder. ${ }^{16}$ Durante esse regime, que durou 27 anos, Zumeta participou mais diretamente da vida política de seu país, representando Gómez, em 1910, na comemoração do centenário da independência da Argentina. No ano seguinte, dirigiu e organizou a celebração do Congresso de Municipalidades. Em 1913, foi diretor de Política do Ministério das Relaciones

que as nações latino-americanas não podiam prejudicar os interesses estrangeiros e logo se esconderem atrás da Doutrina Monroe; afirmou que, em caso de mau comportamento de um país sul-americano, “deixe que o país europeu o espanque” (SMITH, 2008, p. 627-628).

${ }^{16}$ Juan Vicente Gómez, em seu governo, contou com a colaboração de renomados intelectuais da época. Além de Zumeta, contou com Laureano Vallenilla Lanz, Francisco González Guinán, José Gil Fortoul, Pedro Emilio Coll, Manuel Díaz Rodríguez, Pedro Manuel Arcaya, Eloy G. González e Caracciolo Parra Pérez. O apoio de Zumeta à ditadura de Juan Vicente Gómez e sua participação direta nesse período talvez explique o ostracismo ao qual o escritor venezuelano foi relegado a partir dos anos de 1930. Elias Pino Iturrieta considera que esses autores aproveitaram-se da ditadura de Gómez de modo a lucrar com ela, ascendendo política e economicamente (PINO ITURRIETA, 1978).

\section{GANPHLAC}

Revista Eletrônica da ANPHLAC, ISSN 1679-1061, N. 17, p. 254-281, jul./dez. 2014. http://revista.anphlac.org.br/ 
Interiores e, em 1914, se tornou titular do despacho executivo. Entre 1915 e 1932, desempenhou funções diplomáticas representando a Venezuela na Sociedade das Nações, foi plenipotenciário na Itália e na França e presidente da Assembleia das Nações (1930). Faleceu, em Paris, em 1955, aos 95 anos.

\section{A política pan-americana e a reação da intelectualidade latino-americana}

Em fins do século XIX, África e Ásia estavam repartidas entre as potências europeias. Os Estados Unidos, após a queda dos últimos bastiões coloniais na América, se apresentavam como herdeiros para ocupar o vazio de poder deixado pela antiga metrópole espanhola (ZEA, 2000, p. 8).

Neste contexto de ávidos apetites por novas possessões coloniais, a América, assolada por consecutivas lutas internas, se tornava alvo dos interesses europeus e norteamericanos. Em 1899, César Zumeta publicou em Nova York, o folheto El Continente Enfermo, no qual fazia uma breve análise do continente, denunciando os perigos que o cercavam e propondo alternativas para o seu progresso. Segundo esse autor, a era inaugurada no continente com a vitória em Ayacucho, em 1824, chegava ao fim frente aos acontecimentos em Manila, nas Filipinas e em Santiago, em Cuba, após a derrota espanhola para os Estados Unidos na guerra de $1898 .{ }^{17}$ A Espanha, nessa ocasião, foi obrigada a renunciar, em benefício norte-americano, ao seu domínio no Pacífico e no Caribe.

Através desses acontecimentos e com o despontar dos Estados Unidos como uma potência imperialista no continente, Zumeta chamou a atenção para a necessidade de as repúblicas hispano-americanas se precaverem do ambicioso vizinho do norte, cujo grande desenvolvimento, alcançado, sobretudo, após a Guerra de Secessão (1861-1865),

\footnotetext{
${ }^{17}$ Em 1895, quando explodiu mais uma revolta em Cuba pela independência, surgiu o pretexto para os Estados Unidos entrarem na guerra contra a Espanha. Os norte-americanos viram no pedido de apoio cubano à sua luta a oportunidade de iniciarem a conquista do Caribe. O então presidente dos Estados Unidos, Willian Mckinley (1843-1901), com o aval do Congresso, reconheceu como legítima a causa cubana e enviou para a ilha o navio Maine, no intuito de proteger os cidadãos e as propriedades norteamericanas. Em 1898, uma explosão afundou esse navio - as razões do ocorrido permanecem ainda hoje obscuras. Diante disso, os Estados Unidos acusaram a Espanha de ter provocado a explosão, não obstante esta ter se empenhado ao máximo para socorrer as vítimas do incidente e apurar as suas causas, e entraram na guerra vencendo os espanhóis sem maiores dificuldades (JUNQUEIRA, 2001).
}

\section{GANPHLAC}

Revista Eletrônica da ANPHLAC, ISSN 1679-1061, N. 17, p. 254-281, jul./dez. 2014. http://revista.anphlac.org.br/ 
exigia a busca de mercados consumidores e a aquisição de territórios "incultos" para explorar riquezas (ZUMETA, 1961, p. 20).

De acordo com Zumeta, as potências, europeias e norte-americana, já estavam encontrando uma forma diplomática de anular a doutrina Monroe, de modo a adaptá-la à política imperialista dos Estados Unidos. Para o escritor venezuelano, tais negociações, apressadas em repartir territórios, incidiriam principalmente sobre o domínio da América tropical, cujos canais marítimos, grandes vias fluviais e florestas quase virgens e suas bacias hidrográficas despertavam a cobiça das potências (ZUMETA, 1961, p. 21).

Os temores de Zumeta também estavam relacionados com o surgimento do panamericanismo, na década de 1880, que ocupou por muitos anos o cenário político e intelectual do continente americano. Convém lembrar que a utilização do termo panamericanismo pode ser percebida em dois momentos históricos distintos. A primeira vez que foi empregado remetia-se à oposição à Europa, manifestada pelas colônias americanas que lutaram pela independência, especialmente com a iniciativa de Simon Bolívar, em 1826, de convocar o Congresso do Panamá com o intuito de apresentar seu projeto de união americana. ${ }^{18} \mathrm{Um}$ segundo momento, que é o que nos interessa aqui, é o do pan-americanismo norte-americano, inaugurado com o corolário da declaração de Monroe e dominante a partir do final do século XIX (CASTRO, 2012).

Proveniente de Pan-América, o termo foi cunhado pelos Estados Unidos em 1889, quando planejaram a criação de uma União Americana, visando a diminuir a influência da Europa no continente e, paralelamente, ampliar suas relações comerciais com os demais países americanos. James G. Blaine (1830-1893) foi o principal autor e executor do projeto pan-americano. ${ }^{19}$ Em 1881, quando secretário de Estado, defendeu essa política, mas a oposição do Partido Democrata inviabilizou-a. No final dos anos de

\footnotetext{
18 Aimer Granados, no texto "Congresos e intelectuales en los inicios de um proyecto y de uma conciencia continental latinoamericana”, analisa as propostas de unidade continental entre as décadas de 1820 e 1860, partindo dos congressos de união hispano-americana e dos escritos mais importantes que determinados intelectuais latino-americanos do período produziram a esse respeito (GRANADOS \& MARICHAL, 2009).

${ }^{19}$ Esta doutrina já havia sido defendida anteriormente por políticos como James Buchanan (1791-1868), Jeremiah Sullivan Black (1810-1883) e William H. Seward (1801-1872).
}$$
\text { CANPHLAC }
$$

Revista Eletrônica da ANPHLAC, ISSN 1679-1061, N. 17, p. 254-281, jul./dez. 2014. http://revista.anphlac.org.br/ 
1880, quando o pan-americanismo foi novamente proposto, coube a Blaine, então secretário de Estado, orientar a sua reunião inicial (CASTILLA, 1961, p. 26).

Nas últimas décadas do Oitocentos, os Estados Unidos passaram a despertar, entre políticos e intelectuais da América Latina, suspeitas acerca de suas intenções imperialistas. O cubano José Martí foi um dos primeiros a denunciar essa política panamericana como um pretexto norte-americano para a sua ingerência no continente. Com esse intuito, publicou, em 1889, no La Nación, o artigo "Congreso Internacional de Washington: su historia, sus elementos y sus tendências", texto onde expunha a necessidade de olhar cuidadosamente o convite que os Estados Unidos estavam fazendo aos países americanos (MARTÍ, 1980).

Para Martí, a motivação real do Congresso ao propor o panismo era atender às necessidades comerciais da jovem indústria norte-americana. Além disso, em sua opinião, existiriam também outras questões mais profundas, atrelando a conjuntura econômica à tradicional política de determinados setores daquele país em relação aos países do Sul. Tal política vinha com uma face nova, e seu programa, fundamentalmente comercial, servia de justificativa para atender aos interesses das grandes indústrias financeiras do país (ARDAO, 1986, p. 159).

Além do escritor cubano, outros intelectuais latino-americanos reagiram à política pan-americana. Na Argentina, Uruguai, Venezuela, Brasil e México, muitos se manifestaram contrários a tal política e declararam os perigos que poderiam sobrevir com o pan-americanismo, denunciando o que estava por trás do corolário do monroísmo. Inúmeros artigos publicados nesse período apontavam os riscos que essa doutrina representava, argumentando que a política defendida pelos Estados Unidos não passava de uma artimanha para o domínio de polo a polo do continente.

Na Argentina, Rodríguez del Busto (1848-1926) e Manuel Ugarte (1875-1951) registraram seus temores a esse respeito. O primeiro chamou a atenção para a ação dos Estados Unidos no continente e a pretensão deles de se assenhorear dos países iberoamericanos. Também percebeu no Brasil um provável cúmplice da potência do norte. Em sua opinião, a única alternativa para a América Hispânica impedir o domínio estadunidense era a confederação de todas as nações ibero-americanas (VERÍSSIMO,

\section{GANPHLAC}

Revista Eletrônica da ANPHLAC, ISSN 1679-1061, N. 17, p. 254-281, jul./dez. 2014. http://revista.anphlac.org.br/ 
1986, p. 19). Manuel Ugarte, aludindo ao fato de os Estados Unidos terem estimulado a separação do Panamá da Colômbia, afirmou que isso só poderia fazer supor que a doutrina Monroe, que em um primeiro momento "pareció salvaguardia para toda América”, converteu-se “en instrumento de tiranía” (UGARTE, 2005, p. 75).

César Zumeta, em 1900, publicou em Paris, na revista América, uma nota editorial a respeito da convocação das repúblicas hispano-americanas para a Conferência Pan-americana. O convite estadunidense, que foi divulgado em variados jornais da América Latina, acusavam os europeus de criar receios entre os países latinoamericanos e os Estados Unidos e destacava que aquele congresso não se ocuparia de assuntos políticos. De acordo com Zumeta (1961, p. 215), tal convite, ao frisar que não se ocuparia de questões políticas, na realidade o que expressava era que os países convidados não deveriam questionar acerca da República cubana - que desde 1898 estava sob protetorado norte-americano, com a ocupação militar da ilha -, a anexação de Porto Rico ou a convenção de Haia (1899), nem deveria debater a respeito dos interesses do gigante americano nas Antilhas e América Central.

Por essa razão, para Zumeta, a Conferência tinha como principal motivação os negócios, ou o American Business. Entre as propostas da conferência, os Estados Unidos sugeriam a adoção do sistema estatístico fiscal e os regulamentos aduaneiros utilizados por eles. Também propunham a construção de uma estrada de ferro continental, onde cada república deveria construir, por sua conta, o pedaço da linha que lhe corresponderia e os ramais que ligariam seus centros de produção com a grande via férrea. O escritor venezuelano se opunha a essas propostas e argumentava, contra isso, que estradas de ferro deveriam ser criadas pelo tráfico que estimulariam, isto é, pelas necessidades de seu desenvolvimento e não pelos sonhos dos trusts americanos, que apenas pretendiam vender suas mercadorias (ZUMETA, 1963, p. 215-216).

Diante disso, o autor afirmava, corroborando a proposta de um seu patriota, que mais importante para a América Latina, seria que fossem canalizados os rios que ligavam o rio da Prata ao Amazonas e este ao Orinoco, abrindo o comércio interior da América. Isso atrairia poderosas indústrias, que se estabeleceriam às margens desses rios, promovendo, por meio da junção das águas, a unidade americana. No entanto, de

\section{GANPHLAC}

Revista Eletrônica da ANPHLAC, ISSN 1679-1061, N. 17, p. 254-281, jul./dez. 2014. http://revista.anphlac.org.br/ 
acordo com Zumeta, tal plano, mais vantajoso para as repúblicas, não seria levado em conta na Conferência Pan-americana, uma vez que os Estados Unidos possuíam questões mais oportunas a serem resolvidas. O único ponto que poderia ser proposto naquela ocasião e que seria interessante para as repúblicas era a constituição de um tribunal arbitral pan-americano, ao qual pudessem ser submetidas todas as diferenças que por ventura houvesse entres os países americanos. Esse tribunal, conforme o autor, era uma necessidade e uma garantia para a América Latina (ZUMETA, 1961, p. 216).

A presença estadunidense no continente, então, foi rechaçada por muitos intelectuais e políticos que, por sua vez, defenderam a necessidade de se afastarem da influência econômica dos Estados Unidos. Contudo, se foram muitos os que se posicionaram contrariamente ao pan-americanismo; não foram poucos, na América Latina, os que viram com bons olhos o estreitamento das relações com os Estados Unidos.

É o caso do diplomata e escritor brasileiro Joaquim Nabuco (1849-1910), para quem os Estados Unidos eram o melhor exemplo de uma república presidencialista na América e expressão máxima do progresso industrial (PAMPLONA, 1995, p. 188). Logo, seria adequado que as repúblicas latino-americanas fossem lideradas por esse país (BÁGGIO, 1999, p. 136). Ao contrário de muitos de seus contemporâneos, Nabuco não acreditava que os Estados Unidos tivessem intenções imperialistas na América Latina.

Artur Orlando da Silva (1858-1916), ensaísta e político brasileiro, como Nabuco, também foi defensor e propagandista do pan-americanismo. Porém, não deixou de destacar as intenções expansionistas dos Estados Unidos, as quais, segundo ele, eram implícitas à doutrina de Monroe e à ideia de Destino Manifesto. Artur Orlando considerava o expansionismo importante para o crescimento e desenvolvimento dos países latino-americanos. Em sua opinião, apesar do caráter expansionista, o panamericanismo não possuía intenções imperialistas, e trazia a ideia de uma articulação das três Américas, onde haveria uma comunhão internacional de interesses políticos, econômicos e morais, com o intuito de garantir à civilização futura o seu pleno desenvolvimento (BAGGIO, 1999, p. 165).

\section{CANPHLAC}

Revista Eletrônica da ANPHLAC, ISSN 1679-1061, N. 17, p. 254-281, jul./dez. 2014. http://revista.anphlac.org.br/ 
No já citado artigo "Congresso Internacional de Washington”, Martí apontou inúmeros políticos interessados na política pan-americana, inclusive aqueles que se apressavam em defender mais do que uma aproximação política, desejando um protetorado ou mesmo a anexação àquele país. Citou como exemplo o comportamento de um pretendente à presidência da Costa Rica, declaradamente favorável à anexação de seu país pelos Estados Unidos.

É importante ressaltar que, em fins do século XIX e início do XX, proliferaram intensos debates intelectuais, muitas vezes oriundos de discussões de séculos anteriores e inspirados em grande parte nas teorias cientificistas do século XVIII. Entre esses, o debate entre os defensores da raça latina e os da raça anglo-saxônica, na virada do século XIX para o XX, influenciou sobremaneira a produção intelectual da época. ${ }^{20}$ As derrotas decorridas dos desastres militares da França frente à Prússia (1870); da Itália na Etiópia (1896); o ultimatum inglês, de 1890, que colocou fim ao projeto português de um grande império na África austral, da costa atlântica à costa do Índico; e a crise em que a Espanha mergulhou após 1898 intensificavam as conjeturas a respeito da decadência do mundo latino (MATOS, 2001, p. 150).

Com efeito, foi recorrente, nessa época, a associação dos problemas da América Latina à herança de raça que esses países teriam recebido durante séculos da Espanha e de Portugal, o que contribuiria para seu atraso. ${ }^{21}$ Já os Estados Unidos, sendo oriundos dos anglo-saxões, percebidos como povos superiores, estariam mais bem preparados para alcançar os ideais de civilização e progresso. Não à toa, muitos intelectuais latinoamericanos, impressionados com a organização política e a modernização econômica dos Estados Unidos, passaram a incentivar uma aproximação e mesmo a adoção daquele modelo de desenvolvimento. E alguns, mais exaltados, chegaram a defender a anexação de seus países aos Estados Unidos.

\footnotetext{
${ }^{20}$ A respeito do debate entre latinos e anglo-saxões no contexto da guerra hispano-americana, cf. QUIJADA, Mónica. Latinos y anglosajones. El 98 en el fin de siglo sudamericano. Hispania, 1997, v. LVII/2, n. 196, p. 589-609, 1997.

${ }^{21}$ Desde meados do século XIX, muitos intelectuais latino-americanos culparam a colonização ibérica pelo atraso do continente. Exemplos disso são os trabalhos dos chilenos José Victorino Lastarria (18171888) e Francisco Bilbao (1823-1865); dos argentinos Domingo Faustino Sarmiento (1811-1888); Juan Bautista Alberdi (1810-1884); dos mexicanos José María Luis Mora (1794-1850) e Francisco Bulnes (1847-1924) e do peruano Javier Prado y Ugarteche (1871-1921).
}

\section{GANPHLAC}

Revista Eletrônica da ANPHLAC, ISSN 1679-1061, N. 17, p. 254-281, jul./dez. 2014. http://revista.anphlac.org.br/ 
Portanto, a política pan-americanista, apesar dos contundentes ataques por parte de expoentes da intelectualidade latino-americana, teve nela também os seus defensores, que percebiam nos Estados Unidos um exemplo a ser seguido. Ao longo do século XX, o pan-americanismo sofreria muitas transformações. ${ }^{22}$ As tradicionais críticas a essa política, aos poucos, foram dando espaço a um apoio cauteloso ao que se tornaria o interamericanismo. ${ }^{23}$ Não obstante, é importante esclarecer que a transformação não foi imediata, mas sim paulatina e gradual, à medida que se desenvolvia a Segunda Guerra Mundial e aumentava o temor dos movimentos fascistas na Europa (PITA, 2009, p. 253).

\section{Repercussões do pan-americanismo e do imperialismo nos escritos de Zumeta}

Em um contexto de pan-americanismo e muita desconfiança em relação à política externa dos Estados Unidos, intelectuais latino-americanos se empenharam em denunciar os perigos que cercavam o continente. De acordo com Zumeta, as nações só poderiam aspirar a ser tratadas com alguma seriedade entre as potências se lograssem um equilíbrio de forças. Segundo ele, a doutrina que se apresentava naquele momento poderia ser enunciada assim:

Los pueblos que no saben o no pueden explotar las riquezas de su suelo, y poblar las soledades que el acaso geográfico, o el político encerró dentro de sus fronteras, menoscaban en esa medida la labor universal, y es altamente moralizador que los más aptos y laboriosos ocupen lo que la incuria mantiene ocioso. Los bosques son del leñador, los campos de quien los cultiva; los ríos de quien los canaliza y navega. Es la brega inmemorial de los pueblos y las razas que representan las más avanzadas formas del progreso, contra los pueblos

\footnotetext{
${ }^{22}$ Nos anos de 1930 o pan-americanismo sofreu uma série de mudanças, uma vez que a política externa dos Estados Unidos passou por uma revisão e foi implementada uma política de "boa vizinhança" a partir da vitória do democrata Franklin Delano Roosevelt (PITA, 2009, p. 253). Sobre os Estados Unidos em fins do século XIX e XX, ver: PAMPLONA, Marco Antonio. Revendo o sonho americano: 1890-1972. São Paulo: Editora Atual, 1995.

23 A partir de 1948, houve uma mudança terminológica do termo pan-americanismo para interamericanismo, que está relacionada à criação da Organização dos Estados Americanos (OEA). A esse respeito, ver: ARDAO, Arturo. Panamericanismo y Latinoamericanismo. In: ZEA, Leopoldo (Org.). América Latina en sus ideas. México: Siglo XXI/UNESCO, 1986.
}

\section{GANPHLAC}

Revista Eletrônica da ANPHLAC, ISSN 1679-1061, Nº. 17, p. 254-281, jul./dez. 2014. http://revista.anphlac.org.br/ 
y las razas que representan los infinitos matices del estancamiento y la barbarie". (ZUMETA, 1961, p. 21)

Era essa doutrina que, segundo o escritor venezuelano, prevalecia e logo seria aplicada, uma vez que a Europa e os Estados Unidos consideravam os latino-americanos inábeis para dominar o seu território. Havia manifestações claras de que esse pensamento estava arraigado e era indiscutivelmente aceito pelas potências estrangeiras. O livro do britânico Benjamin Kidd, intitulado The control of the tropics (1898), era um exemplo disso. Nessa obra, segundo Zumeta, já não se discutia a oportunidade e conveniência de espoliar os latino-americanos, mas sim, analisava-se o sistema de vassalagem político e administrativo que deveria submeter esses países. De acordo com Kidd (apud ZUMETA, 1961, p. 21),

Lo que se disputaban las naciones, era la posesión de la tierra habitable por la raza blanca. Se inicia ahora otra gran rivalidad, la de heredar los trópicos, no en el sentido de poseerlos, porque ya los pueblos más civilizados de la tierra han dejado atrás ese criterio, sino en el de dominar esas regiones, según determinado plan.

Assim, frente às evidências de que a independência e a soberania da América Latina estavam ameaçadas, era preciso buscar meios para conservá-las. Zumeta atribuía à difícil situação do continente a incapacidade das repúblicas de solucionar problemas fundamentais logo após a independência. Esses deveres consistiam, principalmente, em explorar a riqueza pública em prol do desenvolvimento nacional e resolver os problemas políticos internos. No que concernia às questões externas, o que havia de imperativo, afora a formalização de tratados de comércio e amizade e a delimitação de fronteiras, era o estabelecimento de um acordo entre as repúblicas hispano-americanas para reinterpretar e promulgar a Doutrina Monroe de maneira a incorporar a ideia de "América para os americanos" ao direito público dessas repúblicas. Feito isso, a doutrina perderia o caráter exclusivamente norte-americano, que naquele momento, acabava limitando a própria soberania desses países (ZUMETA, 1961, p. 22).

Desafortunadamente, o século XIX terminava e esses deveres não haviam sido cumpridos. Vozes como a de Simon Bolívar, que aconselhara a união dos povos latino-

\section{CANPHLAC}

Revista Eletrônica da ANPHLAC, ISSN 1679-1061, No. 17, p. 254-281, jul./dez. 2014. http://revista.anphlac.org.br/ 
americanos em uma ou várias confederações para comum defesa de sua soberania e garantia da integridade territorial, foram ignoradas. E isso trazia grandes perigos para essas nações. $\mathrm{O}$ mito ingênuo de que os povos dessa região seriam guerreiros, e que o clima, a geografia e as doenças endêmicas constituíam grandes aliados, caso houvesse alguma pretensão de invasão, deixava o continente ainda mais vulnerável. Segundo Zumeta (1961, p. 23), "La hora critica de nuestra existencia nacional nos sorprende despercibidos a la defensa".

O escritor venezuelano citou o jornal mexicano La Patria, que criticava aqueles que anunciavam os perigos que cercavam o continente. Segundo esse jornal, os temores continentais não passariam de uma desconfiança indigna, e argumentava que os Estados Unidos não pretendiam alcançar uma primazia política na América. Zumeta (1963, p. 179), ironizando o redator do jornal, afirmava que este deveria sair da torre de marfim em que se metera e olhar dentro das fronteiras mexicanas, onde poderia encontrar lições que demonstravam seu equívoco no tocante à amizade entre o México e os Estados Unidos.

Também o Diario del Salvador, publicado em El Salvador, rebatia a "invenção" do chamado perigo ianque, alegando que não passaria de uma invasão comercial e que "la gloriosa bandera estrellada es una bendición para la América". Zumeta (1963, p. 180) lamentava que Ministros de Estado, diplomatas e intelectuais de algumas repúblicas entoassem o hino de admiração aos Estados Unidos.

Com o intuito de esclarecer os indisfarçados intentos de submissão das repúblicas latino-americanos, Zumeta apontou, em várias passagens, como tais intenções eram frequentemente enunciadas pela imprensa dos Estados Unidos e da Europa, cuja opinião preponderante era a de que os povos dessas regiões seriam semicivilizados e incapazes de alcançar o progresso. Essa opinião era comentada pelo publicista M. Godkin, ${ }^{24}$ que afirmou que "la masa en la América española es muy ignorante, y las clases dirigentes muy reducidas y muy corrompidas" (ZUMETA, 1961, p. 26).

\footnotetext{
${ }^{24}$ Edwin Lawrence Godkin (1831-1902) foi um jornalista irlandês que emigrou para os Estados Unidos em 1856. Fundou o The Nation, em Nova York, em 1865. Em 1881, saiu do The Nation para o jornal New York Evening Post, no qual atuou como editor-chefe entre 1883 até 1899.
}

\section{GANPHLAC}

Revista Eletrônica da ANPHLAC, ISSN 1679-1061, No. 17, p. 254-281, jul./dez. 2014. http://revista.anphlac.org.br/ 
Não foram poucos os momentos em que a imprensa norte-americana havia evidenciado seu desprezo pela América Hispânica e sua população. Exemplo disso são as críticas que os jornais The Manufacturer e Evening Post fizeram aos cubanos, no contexto de luta pela emancipação colonial. Em 16 de março de 1889, o jornal The Manufacturer, da Filadélfia, em seu artigo “QQueremos a Cuba?”, havia feito duras críticas aos cubanos, no momento em que estes faziam uma trégua na guerra de independência. Cinco dias depois, o Evening Post, de Nova York, então dirigido por Edwin Lawrence Godkin, reproduziria o mesmo artigo, com o título "Una opinión proteccionista sobre la anexión de Cuba", corroborando as posições defendidas pelo The Manufacturer.

O artigo ressaltava uma discussão, que vigorava na época, acerca da possibilidade de o governo dos Estados Unidos comprar Cuba da Espanha, e destacava alguns pontos, aparentemente positivos, de tal aquisição, como, por exemplo, a posição estratégica da ilha, a produção agrícola, as belezas naturais, a proximidade da Flórida, entre outros. Mas, pouco depois, essa sua linha de argumentação se transformou em críticas contundentes e em oposição vigorosa à anexação de Cuba. Esse artigo questionava os resultados da incorporação à sociedade norte-americana de uma população como a cubana, formada, segundo The Manufacturer, por basicamente três classes: espanhóis, cubanos descendentes de espanhóis e negros. Os primeiros foram descritos como os menos preparados do que qualquer outra raça branca para se tornarem cidadãos americanos, já que têm governado Cuba por séculos com os mesmos métodos de sempre, que aliavam o "fanatismo" à "tirania", à "arrogância fanfarrona" e à “corrupção". Já aos cubanos era atribuída uma série de características, pois, além de herdarem os defeitos da raça espanhola, eram vistos como preguiçosos, afeminados, avessos a qualquer esforço, incapazes, tanto pela natureza quanto pela experiência, de cumprir com as obrigações da cidadania em uma república livre, além do que, as suas "tentativas de rebelión han sido tan lastimosamente ineficaces que se levantan poco de la dignidad de una farsa". ${ }^{25}$ Os negros eram percebidos como expressão de um imutável estado de barbárie.

\footnotetext{
${ }^{25}$ Este artigo pode ser encontrado no site
}

\section{GANPHLAC}

Revista Eletrônica da ANPHLAC, ISSN 1679-1061, N. 17, p. 254-281, jul./dez. 2014. http://revista.anphlac.org.br/ 
Após tais considerações, o artigo sugeria que a única possibilidade de capacitar Cuba a alcançar uma dignidade de Estado estaria na sua americanização completa, na introdução de povos estadunidenses em larga escala na ilha. Todavia, isso não significava que tal sociedade alcançaria o nível da norte-americana, já que a nova população também poderia se degenerar, dadas as condições de Cuba. O artigo “¿Queremos a Cuba?” concluía advertindo que "estos son hechos que merecen cuidadosa atención antes de que se consume [al]gún proyecto para la adquisición de la Isla. Podríamos hacernos de Cuba a un precio muy bajo, y pagarla todavía cara". ${ }^{26}$

$\mathrm{Na}$ Alemanha também se registravam alusões à submissão da América Latina. $\mathrm{O}$ livro Die Deutschen im Tropischen Amerika ${ }^{27}$, de Wilhelm Wintzer, publicado em Munique, em 1900, discorrendo sobre os alemães que residiam na América Tropical, analisava a história da colonização espanhola na América e o estado político, social e econômico em que os países dessa região se encontravam. Ao final, Wintzer concluía que "los habitantes de la América intertropical no han dado hasta ahora sino pruebas de su incapacidad para constituir un orden político estable, que permita el desarrollo gradual de las riquezas de su suelo" (ZUMETA, 1961, p. 34). Consequentemente, os Estados Unidos ou a Europa deveriam se encarregar de explorar a herança de que os latino-americanos não haviam sabido usufruir. Contudo, esse publicista esclarecia que, das nações europeias, os alemães eram os que mais vinham contribuindo para povoar e desenvolver a região do trópico por meio da imigração e do capital.

Zumeta (1961, p. 35) chamou a atenção para o fato de que, enquanto na Alemanha eram previstas as implicações da repartição dos trópicos e buscava-se uma forma diplomática para solucionar os possíveis conflitos que decorreriam disso, na América Latina a descrença nesses perigos levava, muitas vezes, a acusações de que estes existiam apenas nas mentes dos pessimistas. É importante ressaltar que, nessa época, a Alemanha imperial demonstrava um crescente interesse por esse continente. De

http://jose-marti.org/jose marti/historia/anexionismo/manufacturer/manufacturer1.htm (Acesso em: $4 \mathrm{de}$ abril de 2014).

${ }^{26}$ Idem. José Martí, em réplica às críticas, escreveria em 25 de março o artigo "Vindicação de Cuba".

27 O título completo é Die Deutschen im Tropischen Amerika: Mexiko, Mittelamerika, Venezuela, Kolumbien, Ekuador, Peru und Bolivien: mit Übersicht über die wirtschaftlichen, politischen und gesellschaftlichen Verhältnisse dieser Länder.

\section{GANPHLAC}

Revista Eletrônica da ANPHLAC, ISSN 1679-1061, N. 17, p. 254-281, jul./dez. 2014. http://revista.anphlac.org.br/ 
acordo com Robert Smith (2008, p. 625), a potência europeia estava atraída pelo Novo Mundo não apenas em termos econômicos, mas também demográficos e militares. ${ }^{28}$

$\mathrm{O}$ escritor do $\mathrm{El}$ continente enfermo referiu-se novamente ao trabalho de Benjamin Kidd, destacando que este, ao discorrer sobre a inabilidade dos latinoamericanos em explorar e civilizar o seu próprio território, teria afirmado: “Corporaciones y sindicatos extranjeros irresponsables manejan tras los depositarios del poder publico las grandes empresas, y tienden al dominio político. Sólo dos palabras describen la situación: anarquía y bancarrota” (KIDD apud ZUMETA, 1961, p. 26).

Zumeta, ao aludir aos inúmeros exemplos de pretensão de domínio, desprezo e desrespeito à soberania das repúblicas latino-americanas, evidenciados na imprensa internacional, reproduziu os comentários publicados no jornal nova-iorquino Harper's:

Son republicas en el nombre, pero en el hecho son campamentos militares desorganizados. El gobierno no tiene continuidad ni prestigio. Una casa exportadora, una empresa ferrocarrilera, o un banco de tres al cuarto, extranjeros, se le imponen al Ministro de Finanzas, al Presidente, al Gobierno todo y, a veces, le dictan la ley al país. (apud ZUMETA, 1961, p. 26)

Na Inglaterra, ainda segundo Zumeta, Cecil Rhodes (1853-1902), político britânico, teria recomendado a conquista imediata da América Espanhola, a qual, em sua opinião, seria incapaz de oferecer resistência digna de ser levada em conta. Assim, dados todos os perigos que rodeavam a América Latina, Zumeta entendia que não se poderia descuidar do dever de defendê-la. Para tanto, deveria acontecer, antes de tudo, uma mudança nos costumes públicos.

Alguns países da América do Sul, nas últimas décadas, vinham obtendo êxito a esse respeito. A Argentina, para muitos intelectuais, constituía um modelo a ser seguido. Segundo Zumeta, esse país vinha duplicando sua população a partir de um intenso afluxo imigratório, construindo cidades, centuplicando seus rebanhos e desenvolvendo o cultivo em grandes extensões de terras. Com efeito, a Argentina,

\footnotetext{
${ }^{28} \mathrm{Na}$ virada do século XIX para o XX, mais de 350 mil alemães migraram para o sul do Brasil, e cerca de 120 mil para o Chile. Também havia colônias alemãs na Argentina e América Central. Tal imigração contava com o apoio do governo germânico, que incentivava ativamente os colonos a preservar e ampliar as tradições alemãs, financiando igrejas e escolas de língua alemã. (SMITH, 2008, p. 625)
}

\section{GANPHLAC}

Revista Eletrônica da ANPHLAC, ISSN 1679-1061, N. 17, p. 254-281, jul./dez. 2014. http://revista.anphlac.org.br/ 
juntamente com o Chile e o Uruguai, não estaria exposta aos mesmos perigos aos quais estavam submetidas a Venezuela e outras repúblicas do continente.

Apesar dos graves problemas pelos quais passava a América Latina, algumas lições poderiam ser aprendidas com a história militar, em especial a greco-turca (1897) e a hispano-americana (1898), as quais, segundo o escritor venezuelano, estariam repletas de ensinamentos úteis para povos "débeis" como os latino-americanos. O autor destacava três destes ensinamentos que poderiam ser importantes: primeiro, o clima, a geografia e o valor do soldado, naquele momento, já não constituíam fatores decisivos nas batalhas; segundo, que armamento moderno em mãos inexpertas era quase inofensivo; e terceiro, a marinha moderna é ineficaz contra fortalezas situadas a certo nível de elevação, como o provam os Morros de San Juan e de Santiago, em Cuba, quase ilesos depois de repetidos bombardeios. Para Zumeta, uma vez levadas em conta essas lições, cada república deveria, sem perda de tempo, formar uma milícia nacional e adquirir armas para toda a nação, de maneira a

establecer sociedades de tiro en cada parroquia, crear academias militares, proceder al estudio de la defensa del territorio e de las costas y los ríos, y convenir en un plan común de defensa entre los varios grupos geográficos del Centro y del Sur. (ZUMETA, 1961, p. 29)

Posto isso em prática, segundo o autor, as nações latino-americanas não estariam tão vulneráveis aos ataques das potências estrangeiras. E, a partir disso, esses países poderiam também se valer das rivalidades que dividiam as potências e, logo, demarcar os rumos para suas próprias políticas.

A defesa da unidade da América Latina e a denúncia do imperialismo norteamericano e europeu foram temas constantes nos discursos de Zumeta, sobretudo entre 1899 e 1908. Observamos o desânimo do escritor venezuelano no texto intitulado "Panamá y América", publicado no periódico The Puerto Rico Herald. ${ }^{29}$ Ao discorrer sobre os Estados Unidos e sua ingerência no continente, ele advertia que não estava

\footnotetext{
${ }^{29}$ Embora esse texto apareça sem data, é muito provável que tenha sido publicado entre 1904 e 1905, já que o autor afirma que há cinco anos já havia chamado a atenção para os perigos que envolviam a América Ibérica.
}

\section{CANPHLAC}

Revista Eletrônica da ANPHLAC, ISSN 1679-1061, N. 17, p. 254-281, jul./dez. 2014. http://revista.anphlac.org.br/ 
fazendo isso pelos acontecimentos recentes envolvendo o Panamá, ${ }^{30}$ pois, segundo ele, não "surpreende pessoa alguma dotada de razão", nem mesmo mereciam ser comentados se

no constituyesen nueva y definitiva advertencia a la América ibérica y a las potencias europeas de origen latino. Cinco años ha fueron escritos con la misma profunda certidumbre que hoy me acompaña de que malgastaba entonces, como malgasto hoy, tiempo y tinta en la defensa inútil de la libertad e independencia de los pueblos en que una centuria de despotismo ha hecho aborrecibles esos atributos excelsos de la nacionalidad en donde las agencias disociadoras de la más enervante corrupción están matando en los espíritus hasta el germen de toda virtud ínclita, agotan la surgente misma de las energías redentoras y preparan los ánimos a rebajamientos que colmarían la medida de la vergüenza humana. (ZUMETA, 1961, p. 48)

Para Zumeta, os dias "previstos" se aproximavam e, tal como ocorrera com a África, tinha início a repartição de quase todo o continente. Ele criticava a atitude da América Latina ante a invasão iminente que envolvia o Istmo, ${ }^{31}$ caracterizando-a como uma renúncia covarde ao direito e ao dever de solidariedade geográfica, histórica e racial. Para o escritor venezuelano, isso constituía o mais seguro sinal do processo de degeneração precoce em que se encontravam essas nações.

Frente à conquista da África e Ásia, frente ao aniquilamento do Transvaal e Orange, frente às sucessivas lições oriundas do Texas, Porto Rico e Filipinas, do afundamento do Crête-à-Pierrot no Forte de San Carlos, do bloqueio das costas venezuelanas e das manobras para a construção do canal do Panamá, não haveria, segundo Zumeta, "cérebro normal" que pudesse duvidar da sorte que estava reservada ao resto da América. Nesse sentido, a única possibilidade de impedir que a "lei universal" se impusesse "sobre os débeis" era agir a partir de um plano de defesa continental.

Zumeta concluía El continente enfermo defendendo que o dever imediato das repúblicas era "armarem-se". O sentimento de defensa nacional teria que primar sobre

\footnotetext{
${ }^{30}$ Em 1903, o Panamá conseguiu se separar da Colômbia, após incentivo e auxílio dos Estados Unidos. Em 1904 recomeçaram as obras para a construção do Canal do Panamá, que levou 10 anos para ser concluído.

${ }^{31}$ Em referência à questão do Panamá.
}

\section{GANPHLAC}

Revista Eletrônica da ANPHLAC, ISSN 1679-1061, Nº. 17, p. 254-281, jul./dez. 2014. http://revista.anphlac.org.br/ 
todas as desconfianças da política interna, pois estava claro que não era apenas um povo que estava em perigo, mas todo um continente e uma raça. Com efeito, esse autor defendia, em muitas passagens, a unidade latino-americana. Os acontecimentos na Espanha, de acordo com o escritor venezuelano, demonstravam que seus infortúnios resultavam de um "sistema suicida" de recorrer sempre tardiamente aos meios que, oportunamente aplicados, teriam salvado essa nação. Convocava, ao final,

estos países van de prisa no vayamos nosotros lentamente. Los fuertes conspiran contra nuestra independencia y el continente está enfermo de debilidad. El hierro fortifica. Armémonos. Con esta solo previsión podemos alejar el peligro, y aun conjurarlo. Es de nosotros mismos de quien depende nuestra suerte. (ZUMETA, 1961, p. 30)

Assim, o autor criticava os problemas que percebia como comuns à maioria dos países do continente e que contribuíam ainda mais para dificultar a situação. Entre esses problemas, cita a inexistência de cultura intensiva, que deixava enormes zonas agrícolas e de pastagem quase que totalmente improdutivas; florestas e subsolos inexplorados, ou utilizados para a monocultura e vendidos a preços baixíssimos; a ânsia por contratos com especuladores estrangeiros, que acabava estimulando vorazes formas de peculato e sufocava a incipiente indústria; e a oscilação entre anarquia e ditadura, que deixava precárias as garantias individuais, a propriedade e a vida, fazendo com que a grande corrente migratória mediterrânea, segundo Zumeta (1961, p. 23), “adaptable y asimilable a nuestra zona y nuestra raza, ha fluido al Norte y al Sul y esquiva nuestras costas".

É importante perceber que as preocupações de Zumeta, embora estivessem eminentemente ligadas à perda efetiva de território, soberania e independência das repúblicas latino-americanas, também, se relacionava à perda da tradição cultural ibérica. Zumeta considerava vital para as nações, de ambos os lados do oceano, uma colaboração no sentido de que os latino-americanos pudessem oferecer-lhes um mundo, e, em troca, as nações latinas europeias cederiam o excedente de seus braços e capitais. O fortalecimento mútuo se daria, consequentemente, através da junção dos interesses. A Europa latina ainda poderia ajudar as repúblicas a sair da anarquia por meio do trabalho e da ocupação dos espaços desabitados.

\section{GANPHLAC}

Revista Eletrônica da ANPHLAC, ISSN 1679-1061, N. 17, p. 254-281, jul./dez. 2014. http://revista.anphlac.org.br/ 
Dessa maneira, a proposta de Zumeta, muito calcada nas propostas do período, apontava como solução para os problemas latino-americanos a vinda de imigrantes europeus, que pudessem contribuir com seu trabalho e costumes civilizados. Assim, os povos desse continente se salvariam a partir de um grande plano de exploração e colonização de seu território e das relações de amizade e comércio com as raças progenitoras.

Em novembro de 1900, ocorreu em Madri o Congresso Social e Econômico Hispano-americano, ${ }^{32}$ importante instrumento no processo de retomada das relações entre os países latino-americanos e a Espanha, ${ }^{33}$ que haviam se intensificado após o resultado da guerra hispano-americana. O congresso tinha em vista o estabelecimento de contatos entre ambos os lados do Atlântico em variados níveis: político, econômico e cultural.

Em nota editorial na revista America, Zumeta discorreu sobre o congresso. Nesse texto, o escritor venezuelano, entusiasmado com a iniciativa, conclamava Madri, que, vencida, referindo-se à guerra de 1898, voltava a ser a metrópole da América americanizada. Para ele, que participou do congresso como delegado, a união com as nações latinas da Europa deveria ocorrer por todas as formas possíveis, pois o resultado garantiria a resistência às investidas anglo-saxônicas, que, sob o pretexto de defendê-la contra a cobiça europeia, buscavam se apropriar do continente. $\mathrm{O}$ autor considerava que a resistência era uma questão de sobrevivências da raça e, nesse sentido, a união iberoamericana deveria ser o fundamento da cooperação latina.

Desse modo, Zumeta atribuía os problemas pelos quais as nações latinas vinham passando, tanto as europeias quanto as americanas, à desunião entre elas. A unidade saxônica, a seu ver, favorecia o progresso experimentado nesses países. O Congresso Hispano-americano deveria fazer frente ao pan-americano, elucidando suas farsas e,

\footnotetext{
${ }^{32}$ Apesar de o Congresso ter partido de um Decreto Real firmado por Francisco Silvela (1843-1905) na Gazeta de Madri em abril de 1900, ele também foi favorecido pela Exposição Internacional de Paris, que trouxe à Europa grande número de representantes americanos da cultura, sociedade e economia. (MONTÓN G-BAQUERO, 1999, p. 285)

${ }^{33}$ As relações entre as repúblicas hispânicas e a Espanha estavam abaladas desde a primeira metade do século XIX, após os processos de independência. Nas décadas que se seguiram, em alguns momentos as relações foram tensas, devido às pretensões de recolonização da ex-metrópole. Em 1863, por exemplo, a Espanha colocou a sua frota naval frente as costas peruanas, episódio que gerou protestos nas repúblicas hispano-americanas. (GRANADOS, 2009, p. 55)
}

\section{GANPHLAC}

Revista Eletrônica da ANPHLAC, ISSN 1679-1061, N. 17, p. 254-281, jul./dez. 2014. http://revista.anphlac.org.br/ 
concomitantemente, abrindo o espaço hispânico ao pensamento e ao esforço de nuestra América.

\section{Considerações finais}

O escritor venezuelano falava, em seus discursos, em uma perspectiva continental, não se limitando apenas aos problemas de seu país. Ele se dedicou a denunciar o imperialismo norte-americano e europeu, especialmente o alemão, na América Latina, e a defender a necessidade de união entre os países de origem latina, que compartilhavam a mesma língua, tradição e cultura. Ao defender a unidade latina, Zumeta não considerava a superioridade de uma raça sobre a outra, mas sim a necessidade de enfrentar a agressão anglo-saxônica.

Elementos do contexto da época marcaram seus escritos, como a política panamericana e os imperialismos que representavam um perigo efetivo, tanto em termos geográficos quanto políticos e econômicos. Somavam-se a isso os problemas internos das repúblicas hispano-americanas, o que agravava a situação do continente "enfermo". Para Zumeta, muitos países ainda não haviam deixado o estado "semibárbaro" das ditaduras militares e o mau costume de recorrer às armas em qualquer situação, o que poderia levar fatalmente à anarquia. Daí a urgência de constituir governos capazes de garantir a paz e partidos capazes de vigiar para que a lei fosse respeitada.

Paralelamente e em consonância com os discursos racialistas da época, Zumeta defendia a vinda de imigrantes europeus para a América Latina. $\mathrm{O}$ escritor de $E l$ continente enfermo considerava que esses imigrantes trariam seus costumes civilizados e preencheriam as vastas regiões despovoadas, contribuindo para o progresso continental. Apesar disso, é importante esclarecer que, diferente de muitos dos seus contemporâneos, Zumeta não atribuía o atraso da América Latina à conformação biologicamente heterogênea de sua população.

Enfim, César Zumeta, ao diagnosticar o "continente enfermo", identificando os males que afligiam essa região, contribuiu para o fortalecimento de correntes de pensamento latino-americano que buscavam resistir à influência política, econômica e

\section{CANPHLAC}

Revista Eletrônica da ANPHLAC, ISSN 1679-1061, N. 17, p. 254-281, jul./dez. 2014. http://revista.anphlac.org.br/ 
moral, norte-americana e europeia (de tradição anglo-saxônica) e, ao mesmo tempo, indicar soluções para que a América Latina alcançasse os almejados ideais de civilização e progresso, sem, contudo, negar a herança latina. Assim sendo, uma vez resolvidas todas essas questões, os países latino-americanos obteriam o respeito das nações estrangeiras e afastariam os riscos da ingerência externa.

\section{Referências documentais e bibliográficas}

ARDAO, Arturo. Genesis de la idea y el nombre de América Latina. Caracas: Centro de Estudios Latinoamericanos "Rómulo Gallegos", 1980.

- Panamericanismo y latinoamericanismo. América Latina en sus ideas. Leopoldo Zea (Org.), México, Siglo XXI/UNESCO, 1986.

BAGGIO, Kátia Gerab. A "outra América": a América Latina na visão dos intelectuais brasileiros das primeiras décadas republicanas. Tese de Doutorado em História, USP, 1999.

BARRACLOUGH, Geofrey. Introdução à história contemporânea. Rio de Janeiro: Zahar, 1964.

CAPPELlETTI, Ángel J. Positivismo y evolucionismo en Venezuela. Caracas: Monte Avila Latinoamericana, 1994.

CASTILLA, José J. Caicedo. El panamericanismo. Buenos Aires: Roque Depalma, 1961.

CASTRO, Fernando Luis Vale. Pensando um continente: a Revista Americana e a criação de um projeto cultural para a América do Sul. Rio de Janeiro: Mauad X: FAPERJ, 2012.

GRANADOS, Aimer. Congresos e intelectuales en los inicios de um proyecto y de uma conciencia continental latinoamericana, 1826-1860. In: GRANADOS, Aimer \&

\section{CANPHLAC}

Revista Eletrônica da ANPHLAC, ISSN 1679-1061, Nº. 17, p. 254-281, jul./dez. 2014. http://revista.anphlac.org.br/ 
MARICHAL, Carlos. Construcción de las identidades latinoamericanas: ensayos de historia intelectual siglos XIX y XX. México D.F.: El Colegio de México, 2009.

\& MARICHAL, Carlos. Construcción de las identidades latinoamericanas: ensayos de historia intelectual siglos XIX y XX. México D.F.: El Colegio de México, 2009.

JUNQUEIRA, Mary Anne. Estados Unidos. A consolidação da nação. São Paulo: Contexto, 2001.

LUCCA, Rafael Arráiz. Venezuela: 1830 a nuestros días. Breve historia política. Caracas: Editorial Alfa, 2013.

MATOS, Sergio Campos. A guerra hispano-americana (1898): repercussões em Portugal. In: Estudos em homenagem a João Francisco Marques. Vol. II, pp.149-161, 2001.

MONTÓN G-BAQUERO, Isabel García. El Congreso Social y Económico Hispanoamericano de 1900: un instrumento do hispanoamericanismo modernizador. Revista Complutense de Historia de América, pp.281-294, 1999.

OLIVEIRA LIMA, Manoel de. Impressões da América espanhola (1904-1906). Rio de Janeiro: Livraria José Olympio Editora, 1953.

PAMPLONA, Marco Antônio. Revendo o sonho americano: 1890-1972. São Paulo: Editora Atual, 1995.

Una perspectiva 'arielista' entre los hombres públicos brasileños de fin de siglo: Estados Unidos en los escritos de Joaquim Nabuco y Oliveira Lima. In: ARRIAGA, Victor A. Weiss e SUÁREZ ARGÜELLO, Ana Rosa (compiladores). Estados Unidos desde América Latina: sociedad, política y cultura. México: Centro de Investigación y Docencia Económicas, pp.71-90, 1995.

PINO ITURRIETA, Elias. Positivismo y gomecismo. Caracas: Instituto de Estudios Hispanoamericanos, 1978.

PITA, Alexandra. La discutida identidad latinoamericana: debates en el Repertorio Americano, 1938-1945. In: GRANADOS, Aimer \& MARICHAL, Carlos. Construcción de las identidades latinoamericanas: ensayos de historia intelectual siglos XIX y XX. México D.F. : El Colegio de México, 2009.

PRADO, Maria Ligia Coelho. América Latina no século XIX: tramas, telas e textos. 2. ed. São Paulo: Edusp, 2004.

\section{CANPHLAC}

Revista Eletrônica da ANPHLAC, ISSN 1679-1061, N. 17, p. 254-281, jul./dez. 2014. http://revista.anphlac.org.br/ 
2014.

e PELLEGRINO, Gabriela. História da América Latina. São Paulo: Contexto,

QUIJADA, Mónica. Latinos y anglosajones. El 98 en el fin de siglo sudamericano. Hispania, 1997, vol. LVII/2, no 196, 1997, p. 589-609.

Sobre el origen y difusión del nombre 'América Latina' (o una variación heterodoxa en torno al tema de la construcción social de la verdad). Revista de Indias, vol. LVIII. n. 214, 1998.

SMITH, Robert F. Os Estados Unidos e a América Latina (1830-1930). In: BETHELL, Leslie (Org.). História da América Latina de 1870 a 1930. Vol. IV. São Paulo: Edusp; Brasileia Fundação Alexandre de Gusmão, p.609-649, 2008.

UGARTE, Manuel. La nación latinoamericana. Venezuela: Biblioteca Ayacucho, 2005.

VERÍSSIMO, José. A regeneração da América Latina. In: VERÍSSIMO, José. Cultura, literatura e política na América Latina. Seleção e apresentação: João Alexandre Barbosa. São Paulo: Editora Brasiliense, p.17-31, 1986.

ZEA, Leopoldo. 1898, Latinoamérica y la reconciliación iberoamericana. In: ZEA, Leopoldo e MAGALLÓN, Mario (compiladores). 1898 ¿Desastre o reconciliación? México: Fondo de Cultura Económica, p. 7-19, 2000.

ZUMETA, César. El continente enfermo. Caracas: Colección "Rescate”, 1961.

Las potencias y la intervención en Hispanoamérica. Caracas: Colección Venezuela Peregrina, 1963.

\section{Site}

http://jose-marti.org/jose marti/historia/anexionismo/manufacturer/manufacturer1.htm

\section{GANPHLAC}

Revista Eletrônica da ANPHLAC, ISSN 1679-1061, Nº 17, p. 254-281, jul./dez. 2014.

http://revista.anphlac.org.br/ 